\title{
539098
}

\section{Analysis of aircraft, radiosonde and radar observations in cirrus clouds observed during FIRE II: The interactions between environmental structure, turbulence and cloud microphysical properties.}

\author{
Samantha A. Smith \\ Columbia University \\ 2880 Broadway \\ New York \\ NY10025 \\ USA
}

Present affiliation: Room 258, The UK Met Office, London Road, Bracknell, Berks, RG12 2SZ. Phone: 011441344 854079. Email: sasmith@meto.gov.uk

Anthony D. DelGenio

NASA Goddard Institute for Space Studies

2880 Broadway

New York

NY10025

USA

Submitted to J.A.S.

May, 1999

Contact: Anthony Delgenio. Email: adelgenio@giss.nasa.gov 


\begin{abstract}
Ways to determine the turbulence intensity and the horizontal variability in cirrus clouds have been investigated using FIRE-II aircraft, radiosonde and radar data. Higher turbulence intensities were found within some, but not all, of the neutrally stratified layers. It was also demonstrated that the stability of cirrus layers with high extinction values decrease in time, possibly as a result of radiative destabilization. However, these features could not be directly related to each other in any simple manner. A simple linear relationship was observed between the amount of horizontal variability in the ice water content and its average value. This was also true for the extinction and ice crystal number concentrations. A relationship was also suggested between the variability in cloud depth and the environmental stability across the depth of the cloud layer, which requires further investigation.
\end{abstract}




\section{Introduction}

Cirrus clouds play a major role in the earth's radiation budget due to their extensive areal coverage. The representation of cirrus clouds in the current general circulation models (GCMs) is as yet insufficient. Although the gridbox averaged IWC is often diagnosed it is not yet sufficiently accurate, and horizontal inhomogeneity is not even accounted for. Liou and Rao (1996) showed that cloud horizontal variability in cirrus affects the solar reflection and transmission patterns in a way which is dependent on solar zenith angle, while Tsay et al (1996) showed that cloud morphology affects the shape of the angular distribution of reflected radiance, for example.

The atmospheric IWC in large-scale models interacts with the radiative field, so feedbacks develop between the cloud field, atmospheric dynamics and thermodynamics. Cirrus microphysics responds strongly to the dynamics, as observed by Strom et al (1997). For example, cellular structures have frequently been observed embedded within cirrus layers, increasing the variability in the ice water content (e.g. Smith and Jonas, 1996). Turbulent motions alter not only the variability but also the average microphysical characteristic of a cloud. Donner et al (1997) showed that the subgrid turbulent variations in the vertical velocity had a large effect on the average ice water content (IWC). Their model of large scale cirrus produced gridaveraged IWCs which were too low when subgrid scale variabilıty was neglected, especially near jet streams where strong shear produced gravity waves and tucbulence. Introducing a subgrid scale variability in vertical velocity $w$ almost doubled the averi.ge IWCs.

The complex interactions between the cloud and its envir mment need to be simplified if we are to find a method of parameterizing the ice field. The aim of this paper was therefore to investigate the effect turbulence has upon the structure of the observed cirrus cloud layers and the resulting feedbacks of the cloud on the turbulence. We used data from the FIRE-II cirrus campaign, which took place in November and December 1991 , in the region of Coffeyville, Kansas. Groups of instruments at selected surface sites provided continuous observations of cirrus cloud properties via remote sensing, and this is supplemented by ISCCP (International Satellite Cloud Climatology Project) satellite data. Flights were made through a number of cirrus clouds by the NCAR King Air and Sabreliner aircraft, and vertical atmospheric profiles were obtained using balloon-borne sondes.

\section{Cloud Radar}

The Penn State University $94 \mathrm{GHz}$ (or $3 \mathrm{~mm}$ ) radar provided continous vertical profiles of clouds as they drifted over the site. This gives an estimate of the height of cloud base and cloud top, and therefore of cloud depth $\mathrm{D}$, of the clouds that drift over the main operational site in Coffeyville during the time of each flight. The radar data were averaged over 10 second intervals, corresponding to a $300 \mathrm{~m}$ datapoint spacing for a wind speed of $30 \mathrm{~m} \mathrm{~s}^{-1}$, which is comparable to the aircraft microphysical sampling.

Clothiaux et al (1995) describe the radar in detail. The radar data gives very accurate estimates of cloud base height and is very sensitive to large cloud particles. However, the minimum detectable signal for this data was between -25 and $-30 \mathrm{dbz}$. It is therefore likely that the top $20-30 \%$ of the cirrus layers, where the smallest particles are found, will be missed, although this depends on the cloud layer being observed (Mace et al, 1997).

The cloud depths estimated from the radar data were used in those cases where the flight took place over and around Coffeyville itself (usually within $40 \mathrm{~km}$ of Coffeyville). With typical wind speeds at cirrus levels of at least $30 \mathrm{~m} \mathrm{~s}^{-1}$, the cloud laye, advects $216 \mathrm{~km}$ or more during two hours, the typical duration of a flight. So a $40 \mathrm{~km}$ distance between the centre of a flight track 
and the position of the radar is insignifiant in comparison and the two in effect sample the same cloud layer. There were some flights which took place in other areas. In these cases, when the entire flight was more than $100 \mathrm{~km}$ away from Coffeyville, the radar data was unrepresentative of the area sampled by the aircraft, and therefore the cirrus cloud depth was estimated from the aircraft profiles and runs.

\section{Aircraft Microphysical Measurements}

Eighteen of the flights made by the NCAR King Air and Sabreliner aircraft during the FIRE-II field campaign have been analysed. Flight patterns generally consisted of a profile to sample the vertical structure of the atmosphere along with several horizontal legs within and below the cirrus. The instrumentation onboard the aircraft is described by several NCAR bulletins, but will briefly be described here.

Cloud microphysical data, averaged over 5 minute intervals, were obtained using the PMS 2D-C and 2D-P optical array probes (Knollenberg, 1970; Heymsfield and Baumgardner, 1985). These count and classify the 2-dimensional images of particles passing through the probe. For airspeeds of $100 \mathrm{~m} \mathrm{~s}^{-1}$, the $2 \mathrm{DC}$ probe samples ice crystals in the size range $25 \mu \mathrm{m}$ to $1 \mathrm{~mm}$, and the 2DP probe has a size range of $100 \mu \mathrm{m}$ to $2 \mathrm{~mm}$. The King Air typically flew at airspeeds between 90 and $120 \mathrm{~m} \mathrm{~s}^{-1}$ (the actual speed depends on the altitude). The Sabreliner flew at airspeeds between 165 and $214 \mathrm{~m} \mathrm{~s}^{-1}$, which degrades the $2 \mathrm{DC}$ probe resolution to $50 \mu \mathrm{m}$. Heymsfield and Baumgardner (1985) gives details of the data processing.

The ice crystal size spectra are merged so that data for crystals smaller than $400 \mu \mathrm{m}$ are given by the 2DC probe and data for larger crystals are given by the 2DP. The ice water content (IWC) was calculated from the 5-second average ice crystal size spectra using empirical habitdependent equations for the mass of each ice crystal as a function of diameter, as described by Heymsfield (1977). The resulting IWC is accurate to within a factor of 2 (Heymsfield et al, 1990). The 5-second average ice crystal effective radius $r_{e}$ was found using the definition given by Foot (1988), which preserves the measured IWC and cross-sectional area. This definition of

$\mathrm{r}_{e}$ was used because it is valid regardless of the shape of the ice crystals. The visible extinction $\beta$ was calculated as the geometric optics limit of $2 \times A_{T}$, the total ice crystal cross-sectional area, as in $\mathrm{Fu}$ (1996). An estimate is made of the visible optical depth $\tau$ by multiplying the cloud average extinction by the cloud depth $\mathrm{D}$. The estimated value of $\mathrm{D}$ gives additional uncertainty, so IWC or $\beta$ and their standard deviations are used where possible.

The extinction will be underestimated if a significant fraction of the ice water content resides within the particles which are too small to be detected by the 2DC probe. The FSSP probe samples smaller particles, but was designed for spherical water droplets and the sampling volume for ice crystals is unknown. It therefore tends to over-count ice crystals in the presence of large particles beyond the FSSP probe detection limit (Gardiner and Hallet, 1985), and they are undersized due to response time limitations. The FSSP data was therefore not used.

Platt (1997) examinined ASSP (axially scattering spectrometer probe) data from cirrus and frontal ice cloud. The ASSP measures particles in the $2-30 \mu \mathrm{m}$ size range, giving reasonable numbers but unreliable size spectra. They found that the contribution of these very small particles to the IWC was never greater than $3 \%$, even at the coldest temperatures measured. They can however be important radiatively in cold clouds when large crystals are absent. The maximum contribution to the extinction of $30 \%$ was observed at $-50^{\circ} \mathrm{C}$, but this fell rapidly at warmer temperature levels to a mere $8 \%$ at $-30^{\circ} \mathrm{C}$. Platt et al (1989) found using in-situ and remotely sensed data that $95 \%$ of che extinction occurred for particles larger than $30 \mu \mathrm{m}$ in a low altitude cirrus cloud $\left(-47.3^{\circ} \mathrm{C}\right)$. 
There were 5 cases with cloud top temperatures below $-50^{\circ} \mathrm{C}$, but the majority of the clouds were warmer than this. Kinne et al (1997) analysed FIRE-II cirrus balloonsonde replicator data and found that ice crystals too small to be detected by the aircraft $2 \mathrm{D}$ probes are radiatively of minor importance, contributing only $10 \%$ to the total extinction. Mitchell et al (1996) did not find many small particles in the Citation aircraft replicator data for the 5 December case, but did find a large number of small particles for 22 November. However, this case was not analysed due to a major winter storm which developed during the flight, with multi-layered clouds over the area. In summary therefore, although the small particles may be important radiatively in the coldest cases, they only contain a small fraction of the ice and therefore the average and variability in the IWC can be obtained from the crystals observed by the $2 \mathrm{D}$ probes.

\section{Sampling Problems for Microphysics}

Averages and standard deviations over each horizontal run of ice crystal total concentration $\mathrm{N}, \mathrm{r}_{e}$, IWC and $\beta$ were calculated. The averages and standard deviations were also calculated over each flight, which is more useful for large scale models with limited vertical resolution, and considerably reduces the error due to measurement uncertainties. Such simple statistics can cnly be used for timeseries that are stationary (i.e. the statistical properties are invariant under translation). The length of the runs varied between $50 \mathrm{~km}$ and $300 \mathrm{~km}$, depending on the individual flight pattern. The composite IWC spectra for these flights were found to flatten out in most cases to slopes of magnitude less than 1 at length scales typically between 10 and $15 \mathrm{~km}$, with some flattening out completely to a zero slope (at the integral scale $R$, as in Davis et al, 1996). This means that the timeseries were generally long enough to be considered stationary. The ice spectrum from a flight through cirrus fallstreaks with low IWC values, however. continued to increase at the smallest frequencies despite long run lengths. When comparing the microphysics with turbulence data, only straight horizontal portions of each run were used. The resulting difference in the average and variability of the microphysical parameters was insignificant, indicating stationarity.

The microphysical data were averaged over 5 second intervals to enable the $2 \mathrm{D}$ probes to obtain a large enough sample of crystals to give a reliable size spectrum. This gives a sample spacing of approximately $600 \mathrm{~m}$ for the King Air and $1 \mathrm{~km}$ for the Sabreliner data (depending on the airspeed). This may result in the loss of resolution of very small cellular structures, although often such structures have horizontal scales of $1 \mathrm{~km}$ or greater. Sassen et al (1989) observed complexes of convective structures with horizontal scales of around $1 \mathrm{~km}$ with wider spacings between them. Smith and Jonas (1996) observed convective cells with horizontal scale of $2 \mathrm{~km}$ in a thick frontal cirrus layer from the EUCREX campaign. Starr and Cox (1985) simulated a thin cirrus layer which had cellular structures of horizontal dimension 1 to $1.5 \mathrm{~km}$, the sort of horizontal dimension which appears to be typical of observed cirrus cells. It is therefore possible to capture cellular structures in many cases, but we cannot capture their internal structure.

This study is intended to aid the parameterization of cirrus horizontal inhomogeneity in GCMs which at present do not represent the variability at all. A GCM might at best hope to faithfully represent whatever aspects of the subgrid statistics are related to the large-scale structure and forcing. The small and mesoscale forcings which are present in the real world are unrelated to the large scale and therefore cannot be predicted. Spectra of the ice water content generally had slopes greater than or equal to $5 / 3$, indicating that most microphysical variability is contained in the larger scales anyway. The radiative smoothing scale $\left(\mathrm{l}_{t} \mathrm{D}\right)^{1 / 2}$ (Davis et al, 1997) was calculated. below which the radiance is insensitive to small fluctuations of extinction. Here, $\mathrm{l}_{t}=[(1-\mathrm{g})<\beta>]^{-1}$ is the transport mean free path, with $\mathrm{g}=0.7$ (the asymmetry parameter). 
Values of the radiative smoothing scale range between $50 \mathrm{~m}$ and $150 \mathrm{~m}$, with an average of around $100 \mathrm{~m}$. Horizontal scales smaller than about $100 \mathrm{~m}$ are thus unimportant for cirrus radiative properties.

\section{Aircraft Turbulence Measurements}

Air velocities with respect to the aircraft are obtained from a de-iced radome gust probe (Brown et al, 1983), in which pressure ports are situated on the nose of the aircraft itself. The pressure field resulting from the flow perturbations is used to obtain flow angles. The INS (inertial navigation system) is used to transform wind velocities into the earth frame of reference. Horizontal wind components $\mathrm{u}$ and $\mathrm{v}$ are obtained with a short term relative accuracy $(<10$ minutes) of $\pm 0.1 \mathrm{~m} \mathrm{~s}^{-1}$ and the resolution is $0.012 \mathrm{~m} \mathrm{~s}^{-1}$. The long term sias in vertical velocity $\mathrm{w}$ must be removed as its accuracy is poor. However, perturbations from the mean are reasonable for constant altitude flight legs. Winds are degraded during turns when pitch, roll or bank angles are rapidly changing, and so these sections of data are not used. Standard deviations of the wind velocities $\left(\sigma_{u, v, w}\right)$ are calculated during straight level parts of the horizontal runs.

The wind spectra were also calculated for the straight and level parts of each horizontal run, as described in Smith and Jonas (1996). The best fit straight line was removed from the initial time series, and then $10 \%$ of the data was tapered at both ends using the split cosine bell, to reduce leakage to neighbouring frequency bins. Smooth spectra were obtained by averaging spectral estimates into octave frequency bins (frequency bins $10-5 \mathrm{~Hz}, 5-2.5 \mathrm{~Hz}$, etc for King Air data which has a sampling frequency of $20 \mathrm{~Hz}$ and therefore a Nyquist frequency of $10 \mathrm{~Hz}$ ).

The vertical velocity power spectra were then used to find estimates of the TKE (turbulent kinetic energy) dissipation rate $\epsilon_{w}$, using the method described in Smith and Jonas (1995). The following equation was used:

$$
\epsilon=11.5(f S(f))^{\frac{3}{2}}\left(\frac{f}{T A S}\right)
$$

where $\mathrm{f}$ is the frequency in $\mathrm{Hz}$ (corresponding to a scale $\lambda=\mathrm{TAS} / \mathrm{f}$ ), $\mathrm{S}(\mathrm{f})$ is the spectral density at that frequency and TAS is the true airspeed, or the mean wind speed relative to the aircraft. A frequency of $1 \mathrm{~Hz}$ was chosen for these calculations as this should be within the inertial subrange. The vertical velocity spectra at mesoscales is produced by gravity waves. If there is a small-scale energy source resulting in fully developed, homogeneous, 3-dimensional turbulence, a peak will appear in the vertical velocity spectrum with an inertial subrange (where there are no sources or sinks of energy) at higher frequencies. Energy is handed down to smaller and smaller scales, resulting in a spectral slope of $-5 / 3$ down to the Kolmogorov microscale at which viscous dissipation occurs. Therefore the energy dissipation rate is directly related to the amount of small scale turbulence. If there is no inertial subrange for a run, as might be the case in calm regions, $\epsilon_{w}$ is not really the TKE dissipation rate. However, it's small value indicates that the region is not turbulent. Similarly, values were found from the horizontal wind spectra, with the ratio $\epsilon_{w} / \epsilon_{u}$ indicating whether the turbulence is 2 or 3 dimensional. Wind velocities are only used during straight portions of each run, resulting in shorter timeseries. Turbulent velocity is nonstationary in the inertial subrange where the slope is $-5 / 3$, but the squared velocity gradients are representative of a stationary but highly intermittent dissipation field.

The King Air flies at airspeeds of between 90 and $121 \mathrm{~m} \mathrm{~s}^{-1}$, sampling the wind at a frequency of $20 \mathrm{~Hz}$. This gives a spacing of $7 \mathrm{~m}$ between adjacent datapoints, sufficient for sampling the turbulent velocity field. Turbulence data is not obtained from the Sabreliner, however, as it flies 
at airspeeds between 165 and $214 \mathrm{~m} \mathrm{~s}^{-1}$ with a sampling rate of only $1 \mathrm{~Hz}$, giving a datapoint spacing of $220 \mathrm{~m}$.

High values of vertical velocity standard deviations $\sigma_{w}$ may be due to either high turbulence intensities or to the presence of gravity waves. TKE dissipation rates $\epsilon_{w}$ calculated from the $1 \mathrm{~Hz}$ spectral density are not increased by the presence of gravity waves due to the rapid spectral fall-off in the absence of turbulence, and therefore indicate the amount of small-scale turbulence only. To demonstrate this, figure 1(a) shows $\epsilon_{w}$ plotted against $\sigma_{w}$ for all of the King Air runs. It can be seen that in many cases, $\sigma_{w}$ is quite large while $\epsilon_{w}$ remains small (below $1 \times 10^{-5} \mathrm{~m}^{2}$ $\mathrm{s}^{-3}$ ), indicating that there are gravity waves present but little turbulence. Figure 1(b) shows $\epsilon_{w}$ plotted against the various types of vertical velocity timeseries, which were determined by visual inspection. Timeseries of type 1 are those which are not dominated by wavelike motions, with varying turbulence intensities (fluctuating randomly with varying amplitude). For this type of timeseries, the value of $\epsilon_{w}$ depends on the actual turbulence intensity. Figure 2(a) and 2(b) show two examples of this type of time series. Timeseries (a) has a value of $\epsilon_{w}$ equal to $1.77 \times 10^{-4}$ $\mathrm{m}^{2} \mathrm{~s}^{-3}$. Timeseries (b) has a lower turbulence intensity, with vertical velocity perturbations of less than $0.5 \mathrm{~m} \mathrm{~s}^{-1}$ and $\epsilon_{w}$ equal to $1.66 \times 10^{-5} \mathrm{~m}^{2} \mathrm{~s}^{-3}$. Timeseries with $\epsilon_{w}$ of the order of $10^{-5} \mathrm{~m}^{2} \mathrm{~s}^{-3}$ have vertical velocity perturbations below the noise level and are not what could be called turbulent. Type 3 are those timeseries dominated by wavelike motions, like the one shown in figure $2(\mathrm{c})$, and have very small values of $\epsilon_{w}\left(6.2 \times 10^{-9} \mathrm{~m}^{2} \mathrm{~s}^{-3}\right.$ in this case). Type 2 are nonstationary timeseries with turbulence in only part of the run, like the timeseries shown in figure 2(d). The run-averaged spectral density is small (with $\epsilon_{w}$ equal to $1.95 \times 10^{-6} \mathrm{~m}^{2} \mathrm{~s}^{-3}$ ). The highest value of $\sigma_{w}$ from these four timeseries is for case (a), the most turbulent, having a value of $0.5 \mathrm{~m} \mathrm{~s}^{-1}$. However, the value of $\sigma_{w}$ for case (c) is only a little smaller, with a value of $0.4 \mathrm{~m} \mathrm{~s}^{-1}$ due to the wave activity seen in the timeseries. This demonstrates that $\epsilon_{w}$ is the best measure of the amount of turbulence encountered during a run if the effect of gravity waves is to be excluded. However, care must be taken when it falls below a value of approximately $1 \times$ $10^{-5} \mathrm{~m}^{2} \mathrm{~s}^{-3}$. In such cases the vertical velocity perturbations are below the noise level and $\epsilon_{w}$ is no longer a measure of turbulence intensity.

\section{$6 \quad$ Atmospheric profiles}

Although the aircraft made vertical profiles up through the atmosphere, these often do not reach the cloud top. The aircraft move at high horizontal velocity so that aircraft profiles include horizontal as well as vertical variations. Therefore, CLASS radiosonde data were used to obtain the vertical structure of the atmosphere in which the cirrus clouds were located. These sondes were released from Coffeyville and from several other ground sites, and recorded pressure, temperature, dewpoint, relative humidity (RH), horizontal winds, altitude and position during the ascent. In each case, the sonde profile closest to the aircraft flight path in both space and time was chosen. Generally the radiosondes were launched within $50 \mathrm{~km}$ from the aircraft flight track, except in the case of SA07, when the nearest sonde was Arkansas, $100 \mathrm{~km}$ south of the flight track. This one was not used.

Stability and shear were calculated using the following equations:

$$
\begin{gathered}
\text { Stability }=\frac{\partial \theta_{v}}{\partial z} \\
\text { Shear }=\left(\left(\frac{\partial u}{\partial z}\right)^{2}+\left(\frac{\partial v}{\partial z}\right)^{2}\right)^{\frac{1}{2}}
\end{gathered}
$$


where $\theta_{v}$ is the virtual potential temperature, a measure of the buoyancy of the air. Parameters $u$ and $v$ are the horizontal wind velocities in the east and north directions respectively, and $\mathrm{z}$ is height. Thus the Richardson number $\mathrm{Ri}$ is given by

$$
R i=\frac{N^{2}}{\left(\frac{\partial u}{\partial z}\right)^{2}+\left(\frac{\partial v}{\partial z}\right)^{2}}
$$

where $\mathrm{N}$ is the Brunt-Vaisala frequency (the angular frequency with which an air parcel would oscillate if displaced vertically from its equilibrium position in a statically stable environment), given by

$$
N^{2}=\frac{g}{\theta_{v}} \frac{\partial \theta_{v}}{\partial z}
$$

and $g$ is the acceleration due to gravity. This is a measure of stability - the air is locally stable if $\mathrm{N}^{2}$ is positive, and unstable if $\mathrm{N}^{2}$ is negative.

Average cloud-layer values of stability, shear and thus Richardson number were calculated for each case. Local layer values were also calculated in the vertical region of each horizontal run using just the points above and below the run height.

\section{Environmental Structure and Turbulence}

Turbulence at GCM sub-grid scales has a significant effect on the ice water content variability and therefore on the average ice water content, with higher turbulence creating more ice on average in a large scale model (Donner et al, 1997). Figure 3 shows how the vertical velocity standard deviation $\left(\sigma_{w}\right)$ changes when the initial data averaging length is varied for two different flights. For the very calm case shown in (3a), the value of $\sigma_{w}$ decreases at averaging lengths greater than $1 \mathrm{~km}$, but is relatively constant for smaller averaging lengths. For the more turbulence case shown in (3b), $\sigma_{w}$ starts decreasing at even the smallest averaging lengths, with even larger decreases once averaging lengths of $1 \mathrm{~km}$ are reached. This demonstrates the importance of small scale turbulence on the amount of variability present in vertical motions, which is necessary to produce realistic IWC in large scale models (Donner et al, 1997).

It would therefore be useful to be able to parameterize the turbulence intensity using largescale environmental parameters such as the average shear or stability, which are known to affect the turbulent structure of the atmosphere. However, there was no correlation between the cloud average TKE dissipation rate, $\epsilon_{w}$, and the cloud-layer average stability, wind shear or Richardson number. This is because turbulence typically occurs in vertically thin layers which are dynamically decoupled from each other due to intervening layers of high stability. The $\theta_{v}$ profile shown in figure 4 demonstrates the amount of variability in the stability profile over a cloud layer, the extent of which is denoted by solid horizontal lines. (The dashed line denotes the base of the ice supersaturated region). Calculating the average stability over the entire cloud averages out all the individual stable or neutral layers.

The vertical profiles of $\epsilon_{w}$ are also highly variable between different cloud layers. Therefore figure 5 shows $\epsilon_{w}$ plotted against the stability for each individual horizontal aircraft run which was within the cirrus cloud. The value of $\epsilon_{w}$ within layers with stability greater than $0.005 \mathrm{~K}$ $\mathrm{km}^{-1}$ is always small because vertical motions are limited by high stability. As the local stability decreases towards a neutral lapse rate there is a higher probability of significant turbulence. There are some thin neutral layers with $\epsilon_{w}$ up to $4.7 \times 10^{-4} \mathrm{~m}^{-2} \mathrm{~s}^{-3}$. The lack of direct correlation may be partly due to the fact that it is difficult to relate the observed values of 
$\epsilon$ with a local stability value obtained from a sonde ascent which is not exactly coincident in both time and space. The occurence of turbulence in cirrus clouds is spatially and temporally intermittent (Smith and Jonas, 1996), often being produced on small scales by shear through the breaking of Kelvin Helmholtz waves when the Richardson number falls below 0.25 .

Although it is believed that the cloud may affect the stability of the layer in which it resides and therefore the amount of turbulence created, there appears to be no relationship between the cloud optical depth $\tau$ (or the average IWC) and the thermal stability. Nor is it related to the TKE dissipation rate $\epsilon_{w}$. It has been shown by previous studies that thin neutral or unstable layers can be formed in the atmosphere by differential temperature advection either due to a temperature gradient or due to shear (Sassen et al, 1989; Starr and Wylie, 1990). Destabilization due to the cloud itself, which may also act over thin cloud layers, acts on the background profile. Initial profiles vary from case to case. If the environment is initially very stable, even a large amount of radiative destabilization will not produce instability and convection. It would be a useful exercise to compare the cloud optical depth with the stability for different subgroups of initial stability to see if a pattern then emerges. Jensen $e^{+}$. al (1994) found from their modeling study that a larger optical depth produced more turbulenc , forming a well-mixed layer and providing a source of vapour. However, they found that cloud heating was insufficient to produce instability when an initially stable upper tropospheric profile was used. Convection was generated more easily when a larger vertical velocity and initial neutral stability was used.

Whether or not the cloud is destabilized by the radiative profile depends upon the distribution of the cloud extinction with height rather than the optical depth of the cloud. The cloud top region must be optically thick enough for the infrared cooling to be concentrated near cloud top instead of being distributed throughout the cloud. Figure 6(a) shows the run averaged extinction $(\beta)$ values plotted against height for an example case, with the lines through the symbols representing $\sigma_{\beta}$. Again cloud base and top are indicated by solid horizontal lines, while the base of the saturated region is denoted by a dashed line. Also shown in part (b) are the $\theta_{v}$ profiles obtained from the sonde ascents near the start (solid line) and end (dashed line) of the flight. There is a stable layer at a height of $7.3 \mathrm{~km}$ which increases in both strength and depth through the duration of the flight. This corresponds to a minimum in the IWC profile. Above and below this, the profile has developed from a stable one to one which is neutral, a behaviour suggestive of extinction values that enable radiative destabilization to occur. Other parameters also determine the amount of destabilization due to cloud processes, such as the height of the cloud and its depth. The interactions of all these parameters make it difficult to parameterize the amount of stability over a cloud layer in any simple manner, despite the suggested effect of extinction on the local stability.

\section{Horizontal variation in cloud properties}

Figure 7 shows the run averaged in-cloud values of IWC, ice crystal concentration $N$ and extinction $\beta$ against the run-averaged value of their in-cloud standard deviations. There is a linear relationship between the average value and the variation of each of these parameters. Figure 8 shows that this relationship also holds when values are averaged over the cloudy portions of an entire flight. Individual cloud layers are coupled microphysically through the action of fallstreaks which supply lower layers with ice crystals, or moisture if they evaporate, despite the fact that they are decoupled dynamically. Considine et al (1997) showed a similar relationship between the average and the standard deviation of the liquid water path (LWP) of marine stratocumulus clouds observed by Landsat.

The presence of cellular structures in convective cases locally enhances the production of 
ice above that which would be produced in a uniform cirrus layer. This is because the higher vertical air motions within updrafts produce higher supersaturations (Heymsfield, 1977) and crystal residence time is increased (Mitchell, 1994). So the presence of such cellular structures increases the horizontal inhomogeneity in the IWC by an amount depending on the strength of the vertical motions, with larger values within the cells and smaller values between them. At the same time the average IWC value is increased. Inhomogeneity in the generating layer produces horizontal variability in the evaporative cooling rate below cloud through the action of fallstreaks, in which a new cloud layer and turbulence is produced.

Figure 9 suggests a possible inverse linear correlation between the standard deviation of cloud depth $\sigma_{D}$ (as obtained from the radar) and average cloud-layer stability. Layers with lower average stability are more likely to support convective cells, the presence of which increase the variability in cloud depth. It is unfortunate that there are too few datapoints to give statistical significance to this relationship considering the natural variability present. However it is perhaps worth further investigation in other datasets.

\section{Conclusions}

We have investigated ways to determine the turbulence intensity and the horizontal variability in the cirrus clouds observed during the FIRE-II field campaign over Coffeyville, Kansas in November and December 1991. Layers with high stability were found to have very small TKE dissipation rates as vertical motions are suppressed. Higher turbulence intensities were found within some, but not all, of the neutrally stratified layers. In such cases an additional forcing mechanism is required to release the convective instability, such as shear or gravity wave activity below the neutral layer. No correlation was found between cloud averaged stability and TKE dissipation rates due to the decoupling of the dynamics between separate cloud layers, and also due to the patchiness of the occurence of turbulence regions within cirrus clouds. This means that GCM gridbox mean thermodynamic properties can not be used to determine the turbulence intensity in a cirrus layer in any straightforward fashion given the information available at GCM vertical and horizontal resolution. In addition, although it has been demonstrated that the stability of cirrus layers with high extinction values seem to decrease in time as a result of radiative destabilization, it does not appear possible to explicitly predict the resulting stability of a layer within a GCM. This would require a radiative transfer model with a high vertical resolution, while the resolution of a GCM is very coarse.

A simple linear relationship exists between the amount of horizontal variability in the ice water content (IWC) and its average value. This applies to individual run values at a single altitude, but also to the cloud averages. This could aid future cloud inhomogeneity parameterizations (similar relationships have been observed for marine stratocumulus) as it bypasses the need to consider the turbulence intensity, which does not appear to relate to the variability in any simple way.

It was suggested, however, that there might be a relationship between the cloud depth variability and the average stability of the cloud layer. There were too few datapoints to give statistical significance, but it is worth investigating for other datasets. If the relationship is a real one, it could possibly be used to obtain the cloud microphysical variability using a model such as that described in Smith and Delgenio (2000), which reproduces the ice water content probability distribution function from the cloud depth variability.

In general, the dataset used in the present study is too limited as yet to have complete confidence in the derived relationships and it is necessary to investigate whether they hold for cirrus clouds in other regions of the globe and at other times of the year, as well as for other 
cloud types such as altostratus. However, if the results hold for other datasets, they should aid in the future development of parametrizations of cloud horizontal variability for climate models.

\section{Acknowledgements}

This work was supported by the NASA FIRE-II Research Program and the DOE Atmospheric Radiation Measurement Program. The microphysical data were provided by Andrew Heymsfield. 


\section{References}

Brown, E. N., C. A. Friehe and D. H. Lenschow, 1983: The use of pressure fluctuations on the nose of an aircraft for measuring air motion. J. Climate Appl. Meteor., 22, 171-180.

Clothiaux, E. E., M. A. Miller, B. A. Albrecht, T. P. Ackerman, J. Verlinde, D. M. Babb, R. M. Peters and W. J. Syrett, 1995: An evaluation of a $94-\mathrm{GHz}$ radar for remote sensing of cloud properties. J. Atmos. Oceanic Technol, 12, p201-229.

Considine, G., J. A. Curry, and B. Wielicki, 1997: Modeling cloud fraction and horizontal variability in marine boundary layer clouds. J. Geophys. Res., 102, 13517-13525.

Davis, A., A. Marshak, W. Wiscombe, and R. Cahılan, 1996: Scale invariance of liquid water distributions in marine stratocumulus. Part 1: Spectral properties and stationarity issues. $J$. Atmos. Sci., 53, 1538-1558.

Davis, A., A. Marshak, R. Cahalan, and W. Wiscombe, 1997: The Landsat scale break in stratocumulus as a three-dimensional radiative transfer effect: Implications for cloud remote sensing. J. Atmos. Sci., 54, 241-260.

Donner, L. J., C. J. Seman, B. J. Soden, R. S. Hemler, J. C. Warren, J. Strom, and K.-N. Liou, 1997: Large-scale ice clouds in the GFDL SKYHI GCM. J. Geophys. Res., 102, 21745.

Foot, J. S., 1988: Some observations of the optical properties of clouds. II: Cirrus. Quart. J. Roy. Meteor. Soc., 114, $145-164$.

Fu, Q, 1996: An accurate parameterization of the solar radiative properties of cirrus clouds for climate models. J. Climate, 9, p2058-2082.

Gardiner, B. A. and J. Hallett, 1985: Degradation of in-cloud forward scattering spectrometer probe measurements in the presence of ice particles. J. Atmos. Oceanic Technol., 2, p171-180.

Heymsfield, A. J., 1977: Precipitation development in stratiform ice clouds: A microphysical study. J. Atmos. Sci., 34, 367.

Heymsfield, A. J., and D. Baumgardner, 1985: Summary of a workshop on processing 2D probe data. Bull. Amer. Meteor. Soc, 66, 437-440.

Heymsfield, A. J., K. M. Miller, and J. D. Spinhirne, 1990: 27-28 October FIRE case: Cloud microphysics. Mon. Wea. Rev., 118, 2313.

Jensen, E. J., O. B. Toon, D. L. Westphal, S. Kinne and A. J. Heymsfield, 1994: Microphysical modeling of cirrus 2. Sensitivity studies. J. Geophys. Res., 99, 10443-10454.

Kinne, S., T. P. Ackerman, M. Shiobara, A. Uchiyama, A. J. Heymsfield, L. Milosevich, J. Wendell, E. W. Eloranta, C. Purgold, and R. W. Bergstrom, 1997: Cirrus cloud radiative and microphysical properties from ground observations and in situ measurements during FIRE 1991 and their application to exhibit problems in cirrus solar radiative transfer modeling. J. Atmos. 
Sci, , 54, 2320-2344.

Knollenberg, R. G., 1970: The optical array: An alternative to scattering or extinction for airborne particle size determination. J. Appl. Meteor., 9, 86-103.

Liou, K. N., and N. Rao, 1996: Radiative transfer in cirrus clouds. Part 4: On cloud geometry, inhomogeneity, and absorption. J. Atmos. Sci., 53, 3046-3065.

Mace, G. G., T. P. Ackerman, E. E. Clothiaux, and B. B. Albrecht, 1997: A study of composite cirrus morphology using data from a $94 \mathrm{GHz}$ radar and correlations with temperature and largescale vertical motion. J. Geophys. Res., 102, p13581-13593.

Mitchell, D. L., 1994: A model predicting the evolution of ice particle size spectra and radiative properties of cirrus clouds. Part 1: Microphysics. J. Atmos. Sci., 51, 797-816.

Mitchell, D. L., S. K. Chai, Y. Liu, A. J. Heymsfield, and Y. Dong, 1996: Modeling cirrus clouds. Part 1: Treatment of bimodal size spectra and case study analysis. J. Atmos. Sci., 53, 2952-2966.

Platt, C. M. R., 1997: A parameterization of the visible extinction coefficient of ice clouds in terms of the ice/water content. J. Atmos. Sci., 54, 2083-2098.

Platt, C. M. R., Spinhirne, J. D. and Hart, W. D., 1989: Optical and microphysical properties of a cold cirrus cloud: Evidence for regions of small ice particles. J. Geophys. Res., 94, 1115111164.

Sassen, K., D. Starr, and T. Uttal, 1989: Mesoscale and microscale structure of cirrus clouds: 3 case studies. J. Atmos. Sci., 46, 371-396.

Smith, S. A. and A. D. DelGenio, 2000: A simple model of cirrus horizontal inhomogeneity and cloud fraction. Submitted to Quart. J. Roy. Meteor. Soc.

Smith, S. A. and P. R. Jonas, 1995: Observations of the turbulent fluxes in fields of cumulus clouds. Quart. J. Roy. Meteor. Soc., 121, 1185-1208.

Smith, S. A. and P. R. Jonas, 1996: Observations of turbulence in cirrus clouds., Atmos. Res., 43. 1-29.

Starr, D. and S. K. Cox, 1985: Cirrus clouds part 1: a cirrus cloud model., J. Atmos. Sci., 42, 2663-2681.

Starr, D. and D. P. Wylie, 1990. The 27-28 October 1986 FIRE cirrus case study: Meteorology and clouds. Mon. Wea. Rev., 118, 2259-2287.

Strom, J., B. Strauss, T. Anderson, F. Schroder, J. Heintzenberg and P. Wendling, 1997: In situ observations of the microphysical properties of young cirrus clouds. J. Atmos. Sci., 54, 2542-2553. 
Tsay, S., P. M. Gabriel, M. D. King, and G. L. Stephens, 1996: Spectral reflectance and atmospheric energetics in cirrus-like clouds. Part 2: Applications of a Fourier-Riccati approach to radiative transfer. J. Atmos. Sci, 53, 3450-3467. 
Figure 1 The behaviour of TKE dissipation rate $\epsilon_{w}$ obtained from straight horizontal runs of the King Air.

(a) Plotted against vertical velocity standard deviation $\sigma_{w}$.

(b) Plotted against the type of vertical velocity timeseries as described in the text. Type 3 timeseries are dominated by waves while type 1 timseries are not, having varying amounts of turbulence. Type 2 has turbulence in part of the timeseries.

Figure 2 Examples of the types of vertical velocity timseries referred to in Figure 1.

(a) Type 1, dominated by turbulence.

(b) Type 1 again, but with much lower turbulent intensity.

(c) Type 3, dominated by waves.

(d) Type 2, turbulent in only part of the timeseries.

Figure 3 Variation of vertical velocity standard deviation $\sigma_{w}$ with the length over which the datapoints were averaged.

(a) A very calm case.

(a) A turbulent case.

Figure 4 An example of a virtual potential temperature profile. The solid horizontal lines indicate the cloud boundaries, while the dashed line delineates the base of the region which is saturated with respect to ice. Run heights are marked on the right axis.

Figure 5 The TKE dissipation rate $\epsilon_{w}$ calculated from King Air runs plotted against the local layer stability obtained from the nearest sonde.

Figure 6a Example of an extinction profile. Symbols show the average value at each height while the lines through the symbols give the standard deviations. Cloud boundaries are marked by solid horizontal lines, and the dashed line shows the base of the (ice) saturated region.

Figure $6 \mathrm{~b}$ Sonde virtual potential temperature profiles. The solid line is the profile most representative of the start of the flight, while the dashed line is a profile near the end of the flight.

Figure 7 The standard deviation of microphysical parameters plotted against their average values for each horizontal aircraft run.

Figure 8 The standard deviation of microphysical parameters plotted against their average values for each cirrus cloud.

Figure 9 The standard deviation of the radar-derived cloud depth plotted against the stability averaged over the depth of the cloud layer. 

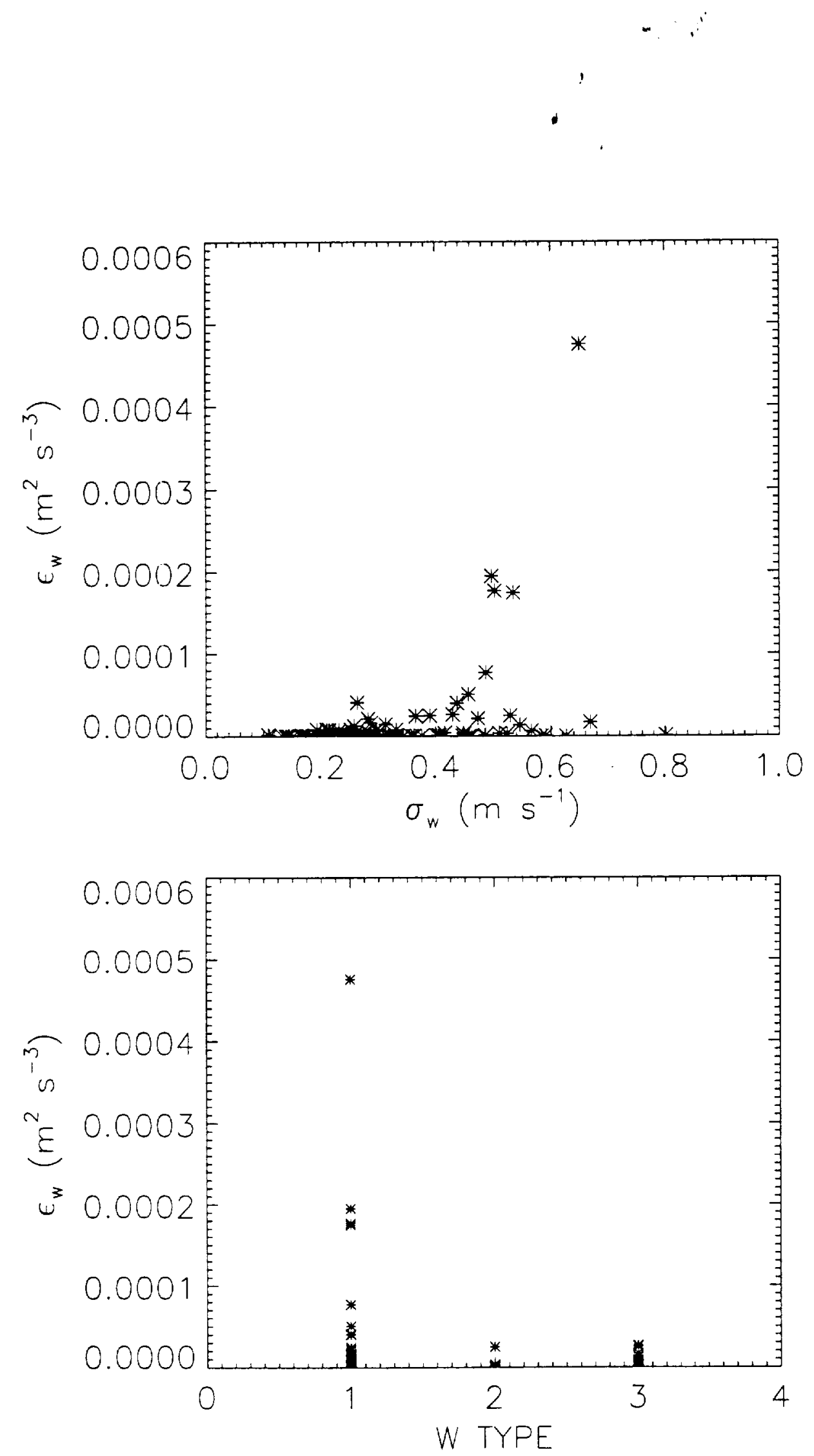
KA08: W timeseries: R1.3 to R1.3

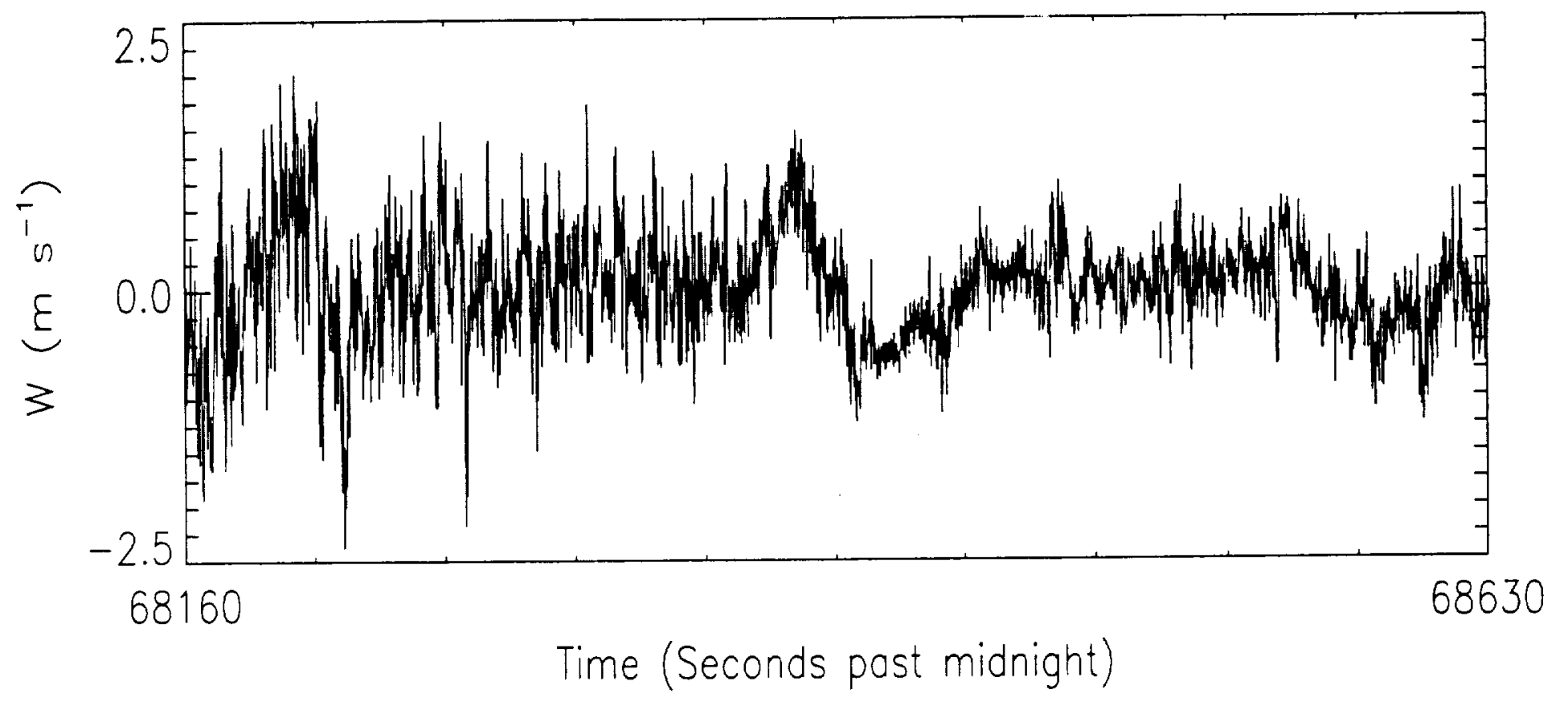




\section{KA14: W timeseries: R7.1 to R7.10}

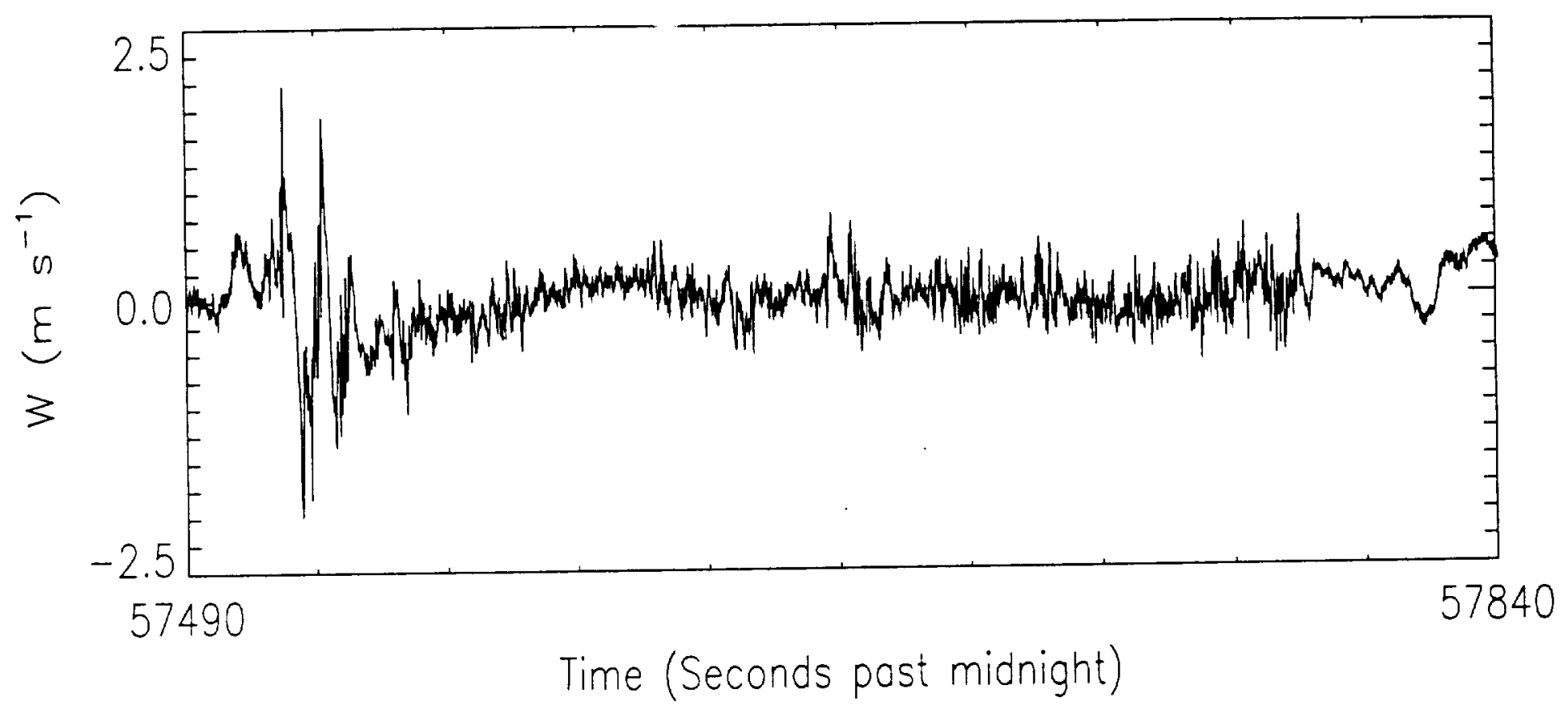


KA05: W timeseries: R4.3 to R4.3"

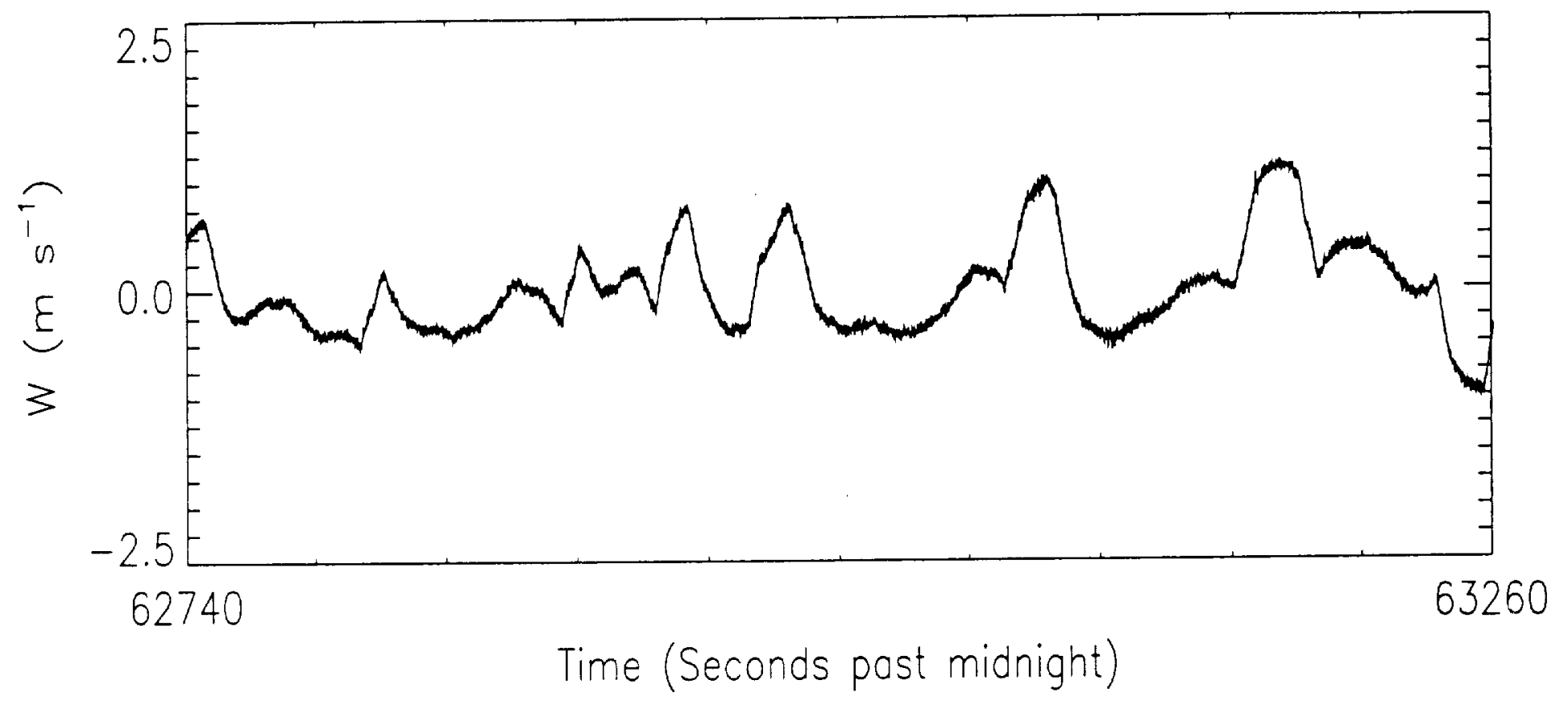


KA13: W timeseries: R2.2 to R2.2

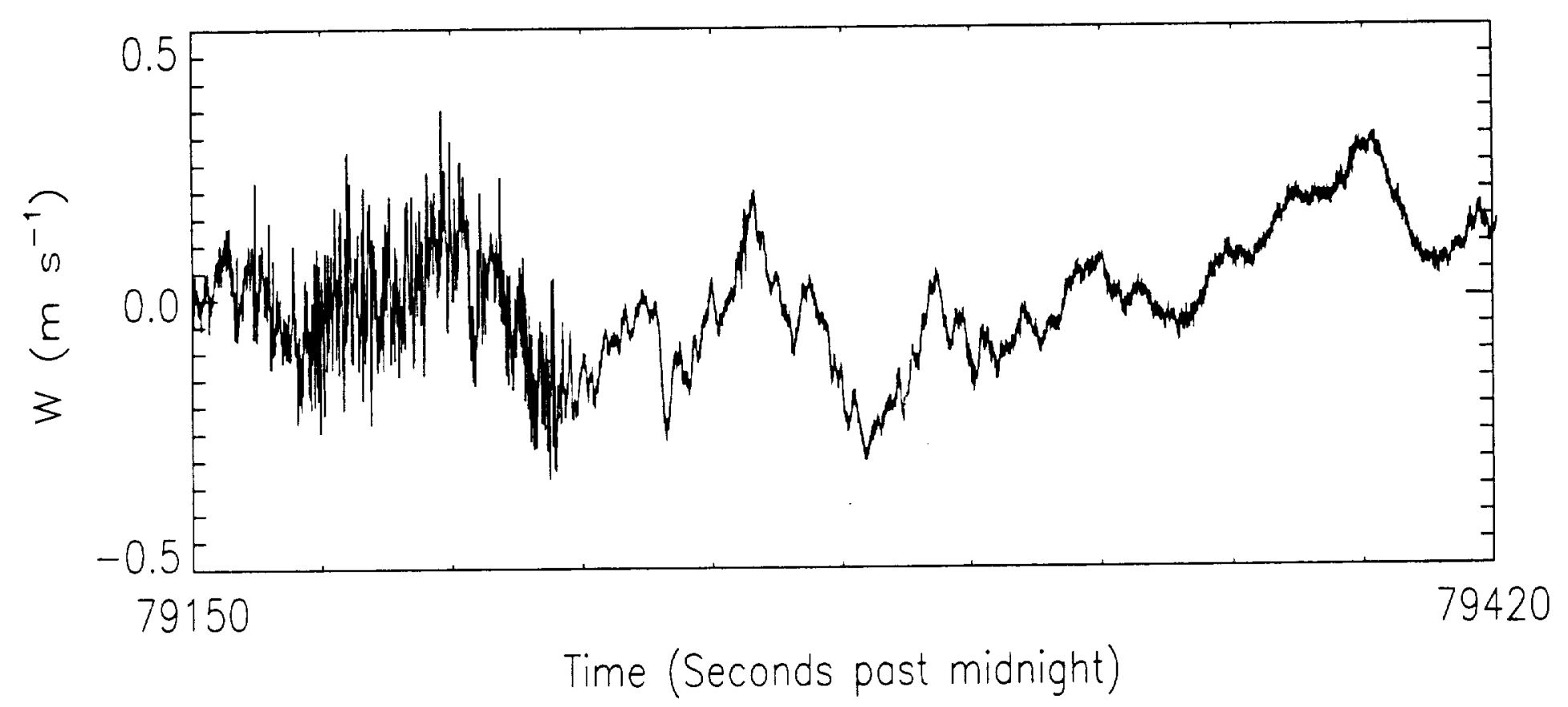




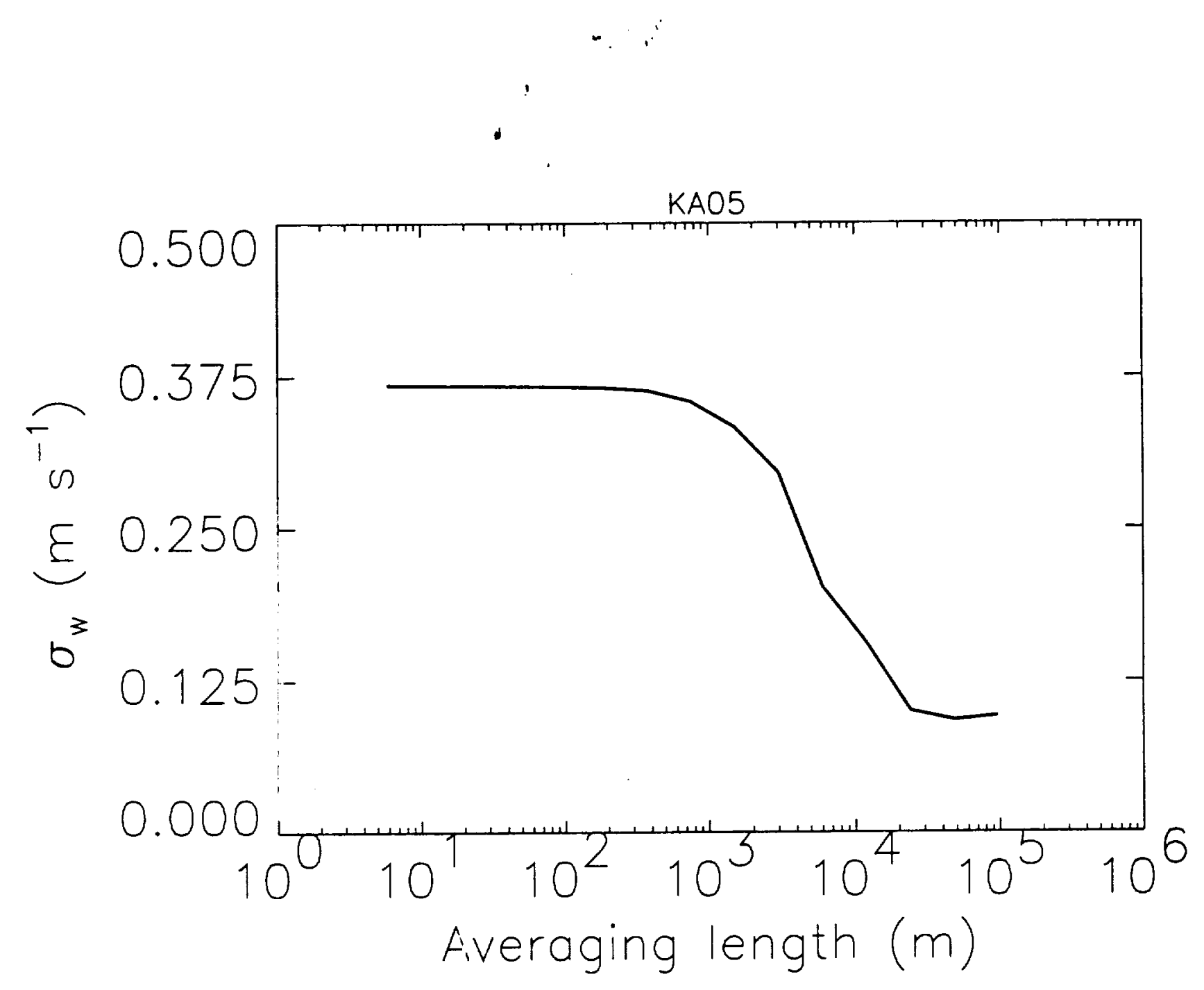




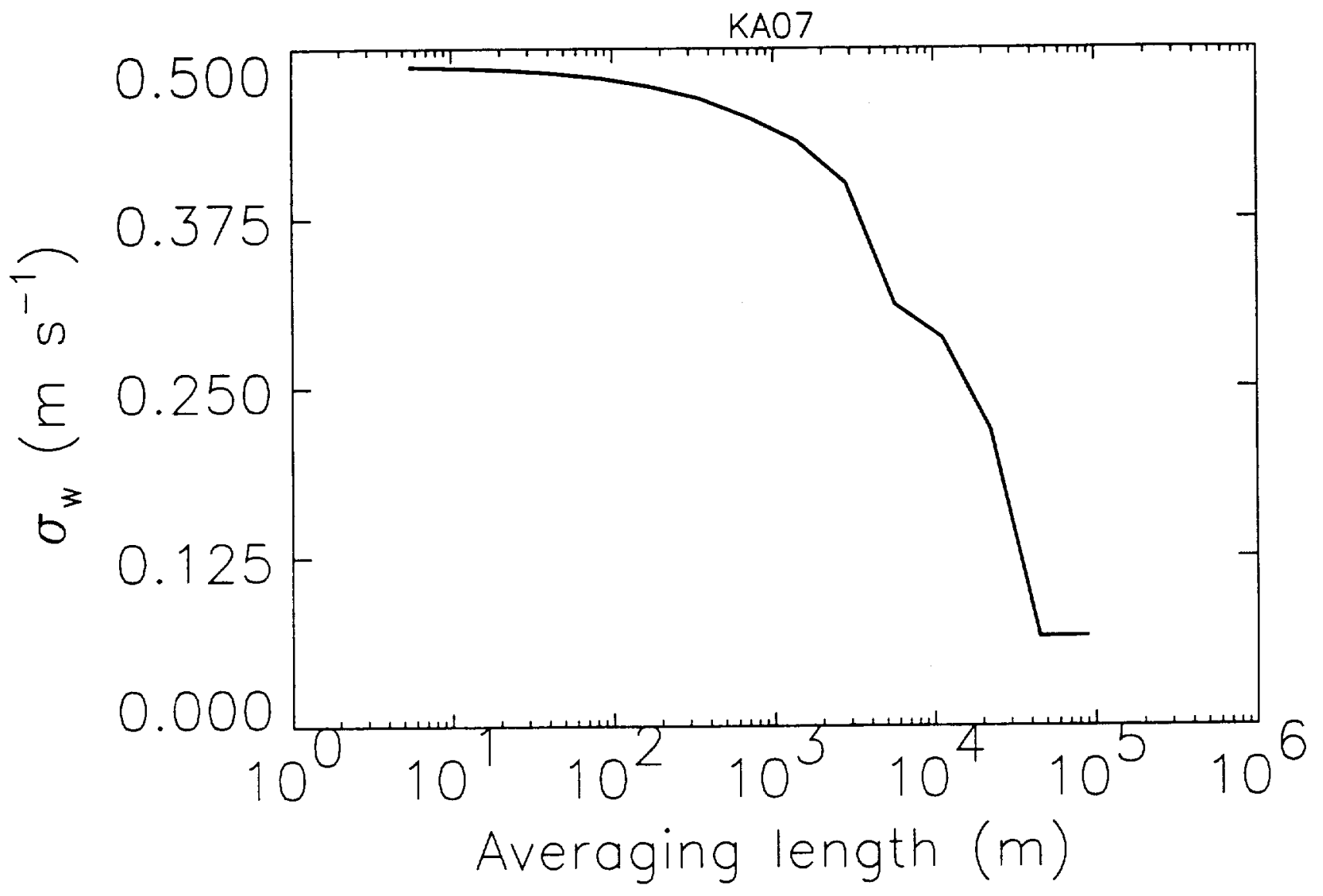




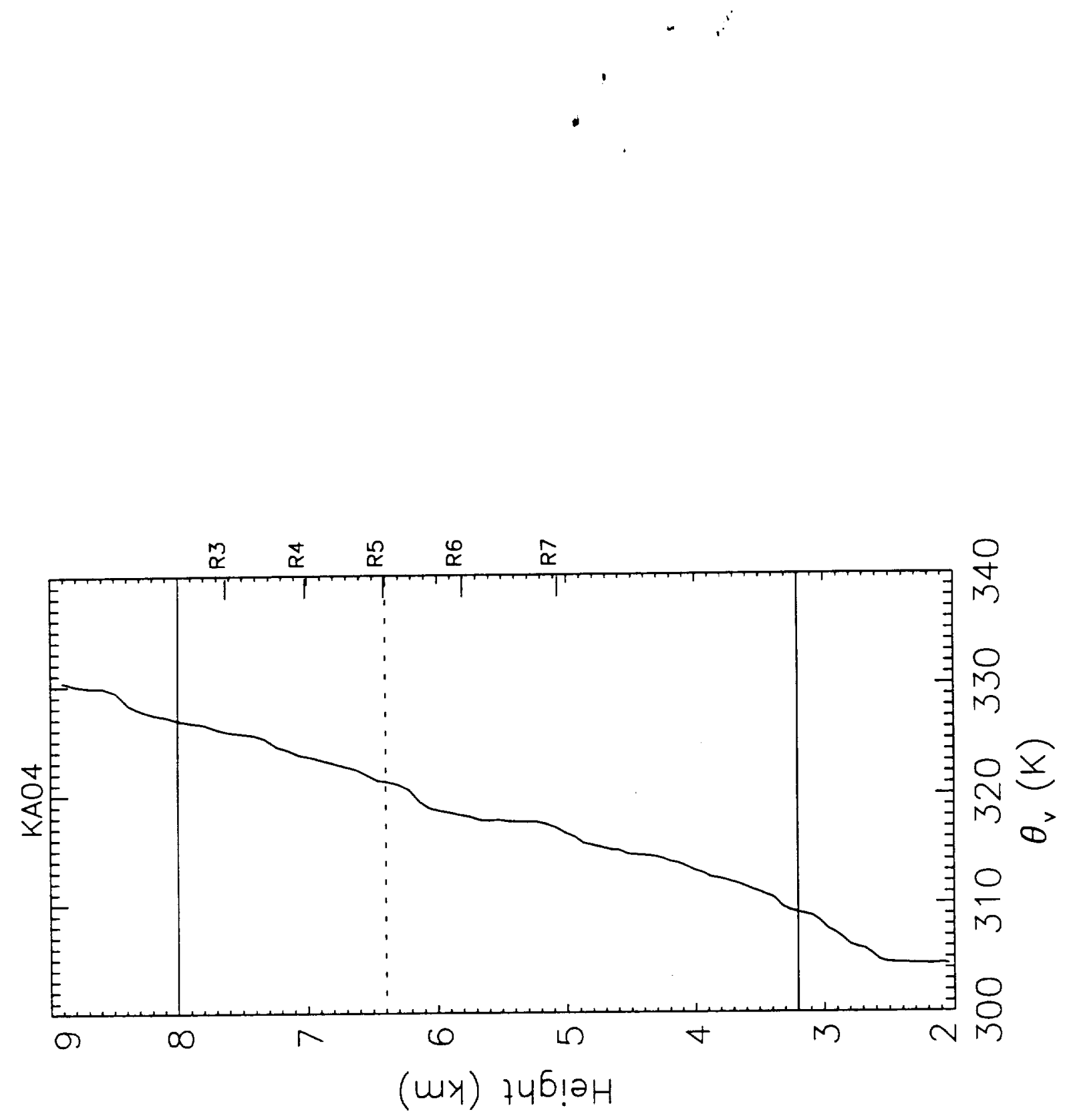



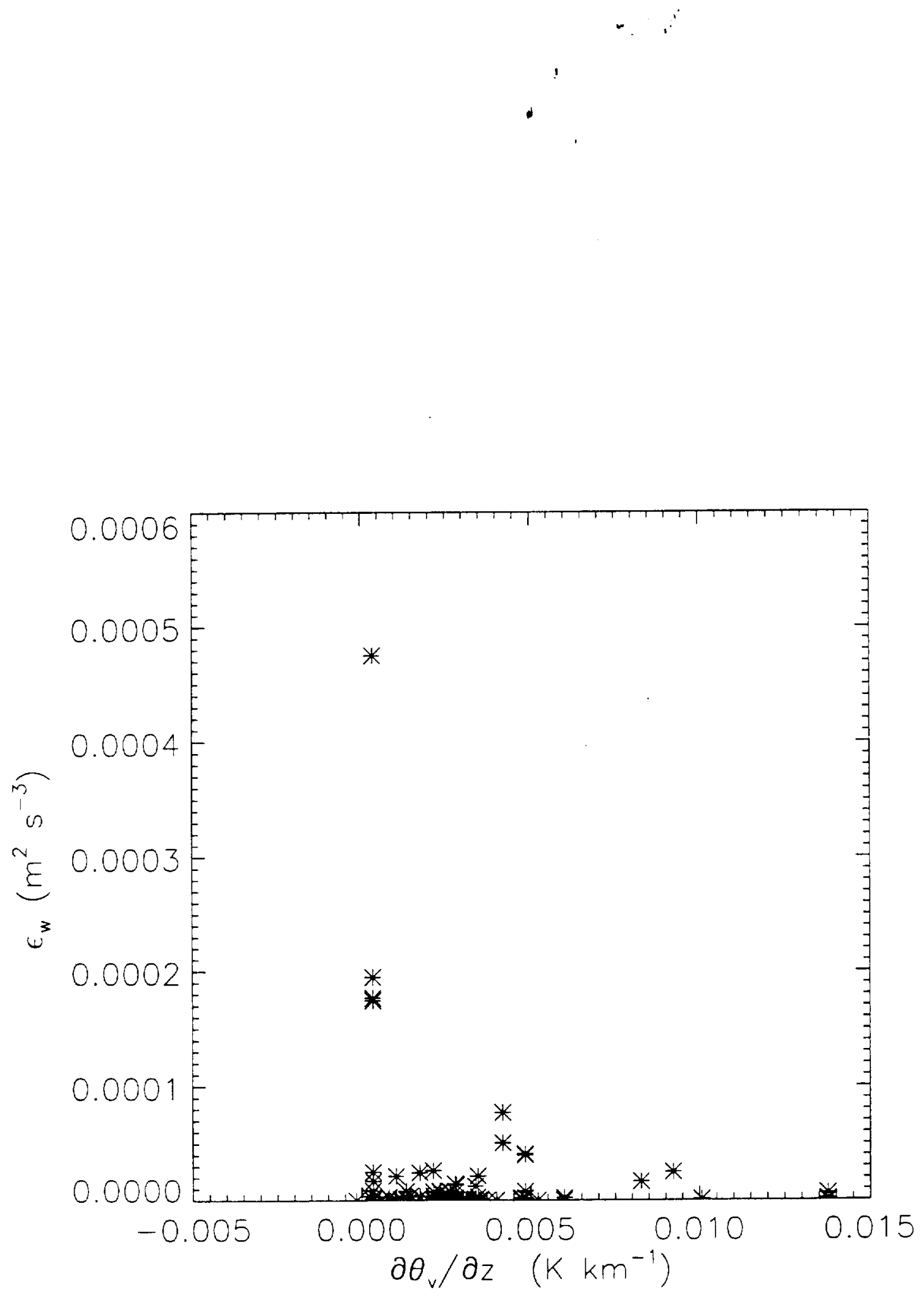


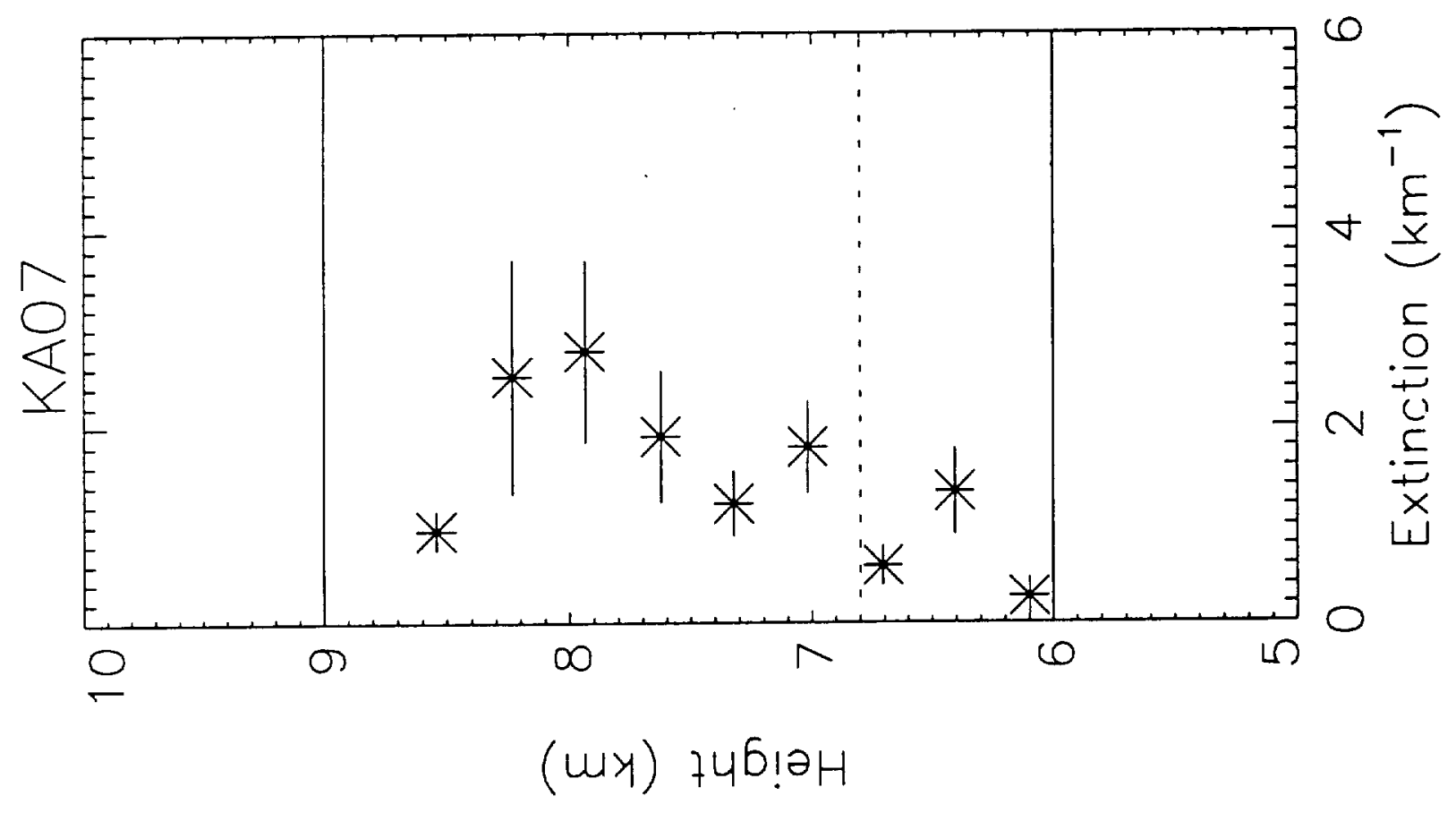




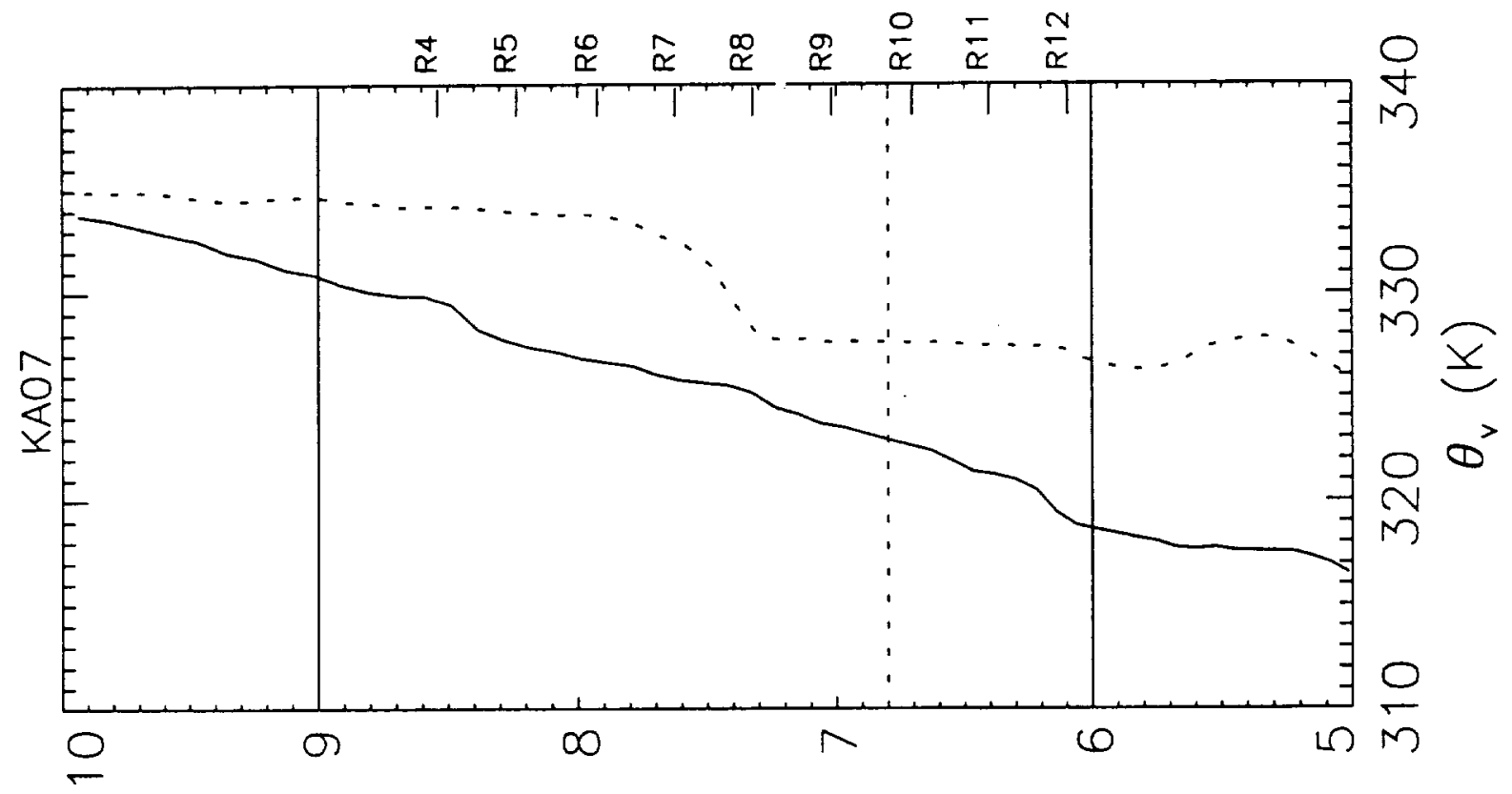

(wy) $746 ! \partial H$ 


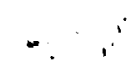

!

$\downarrow$

,

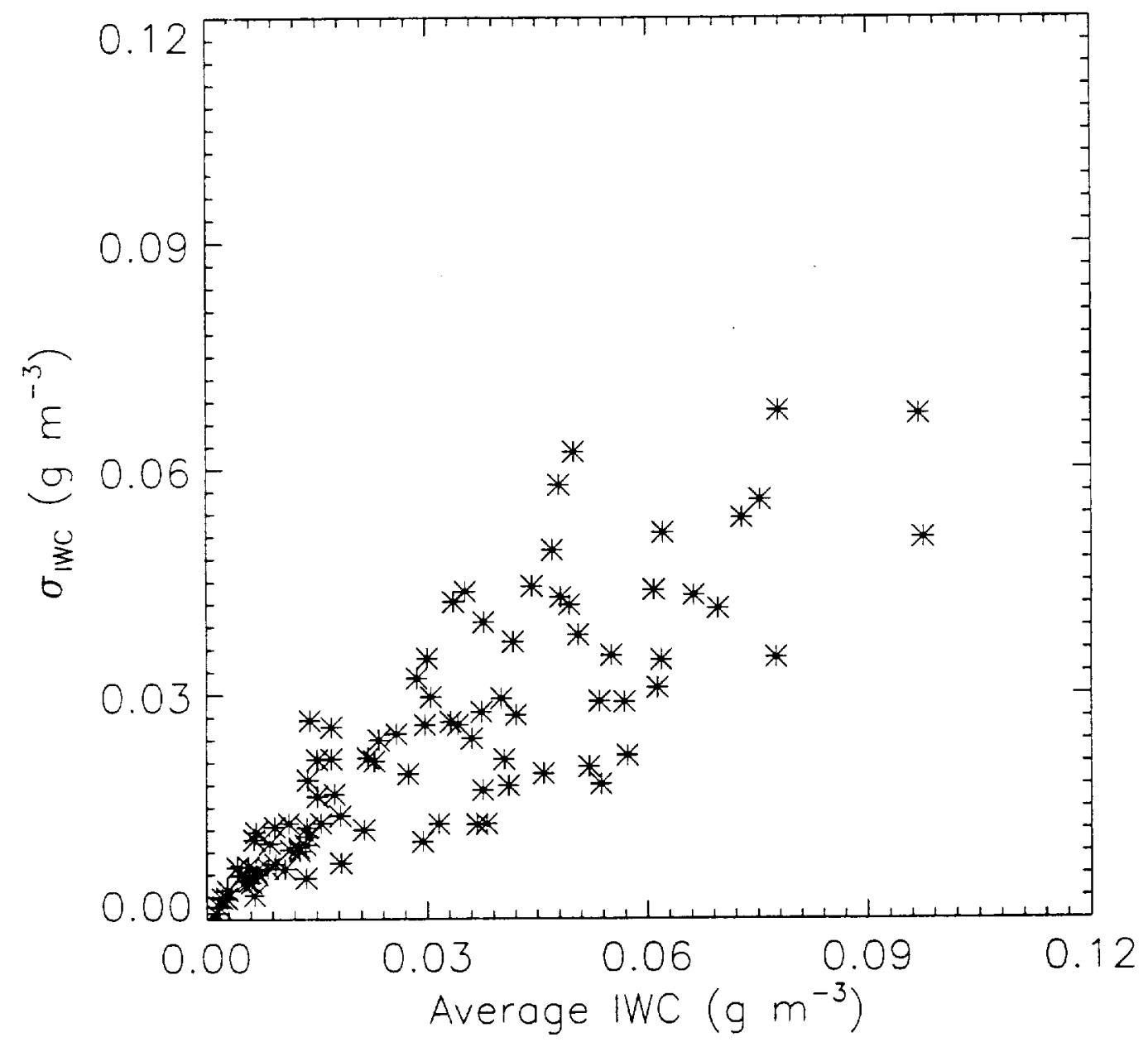


.

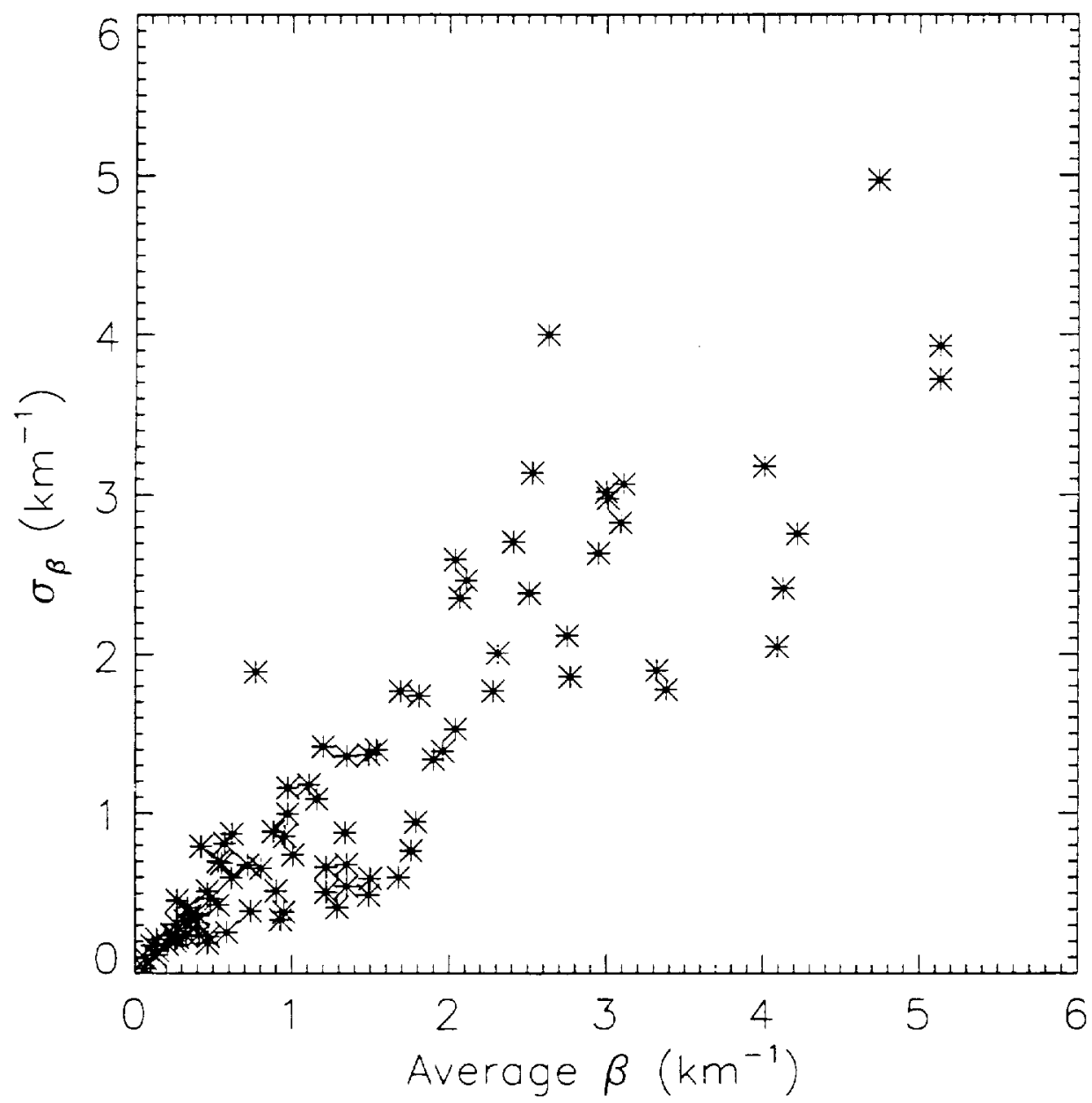




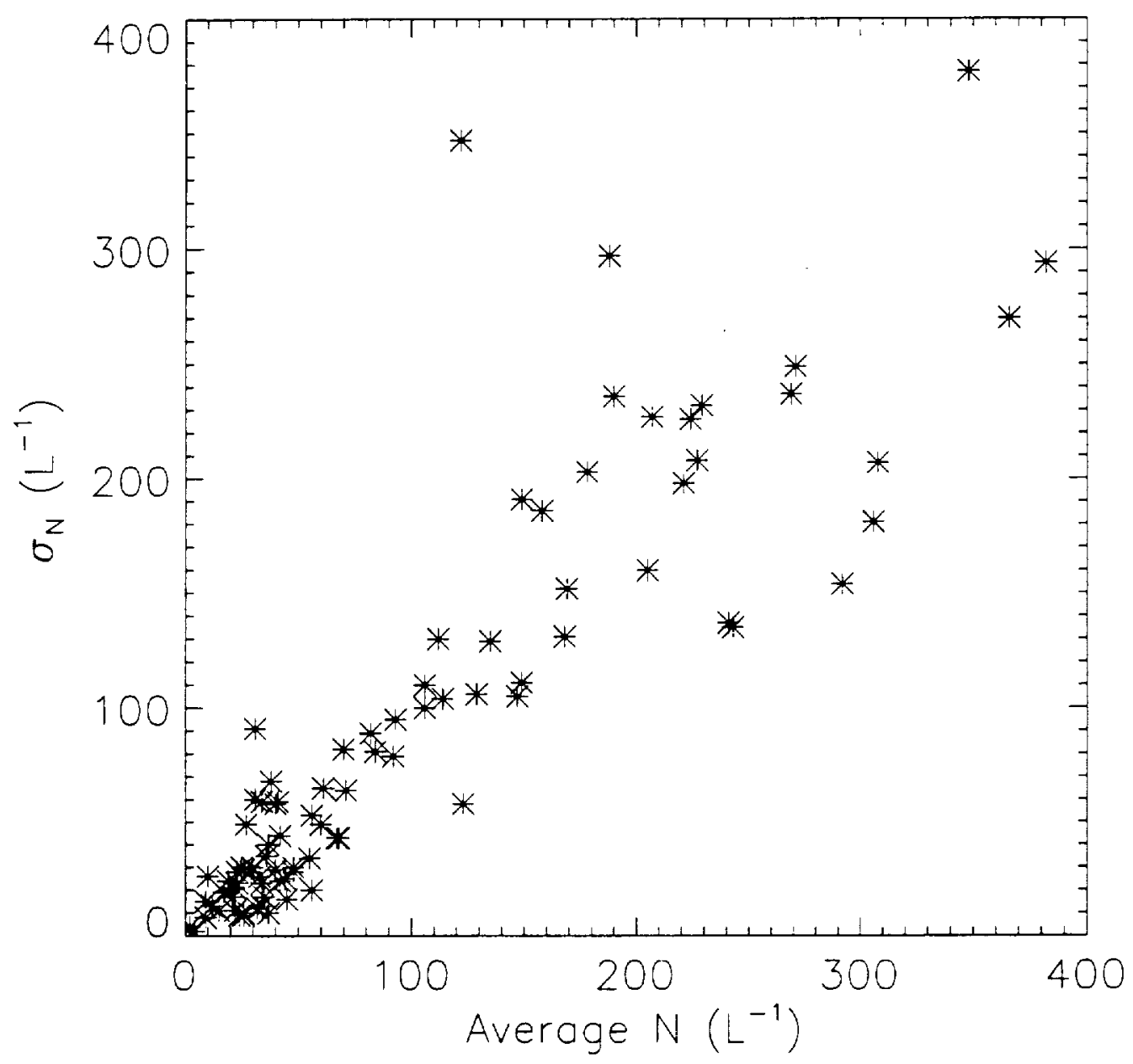




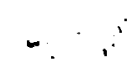

!

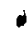

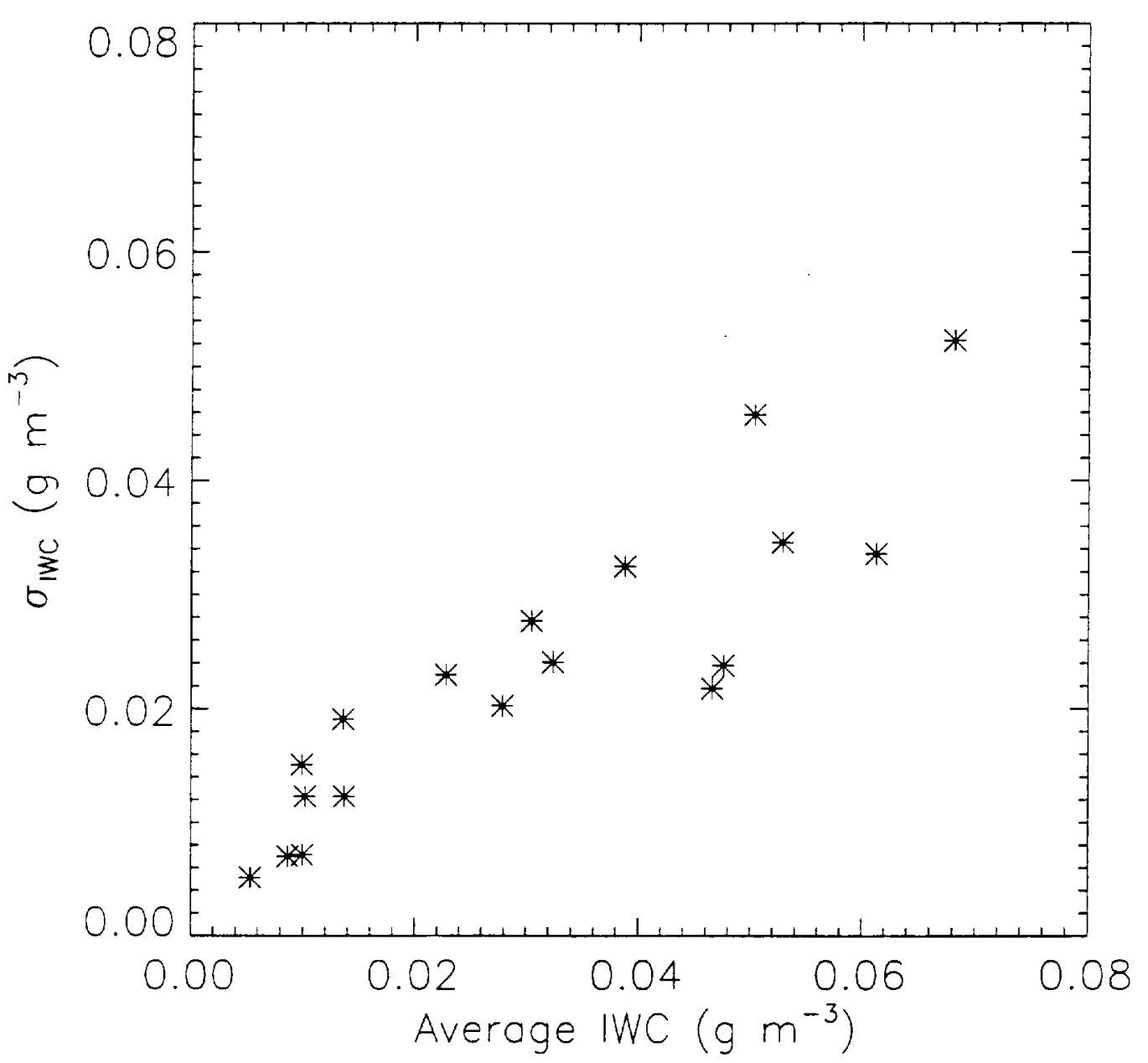




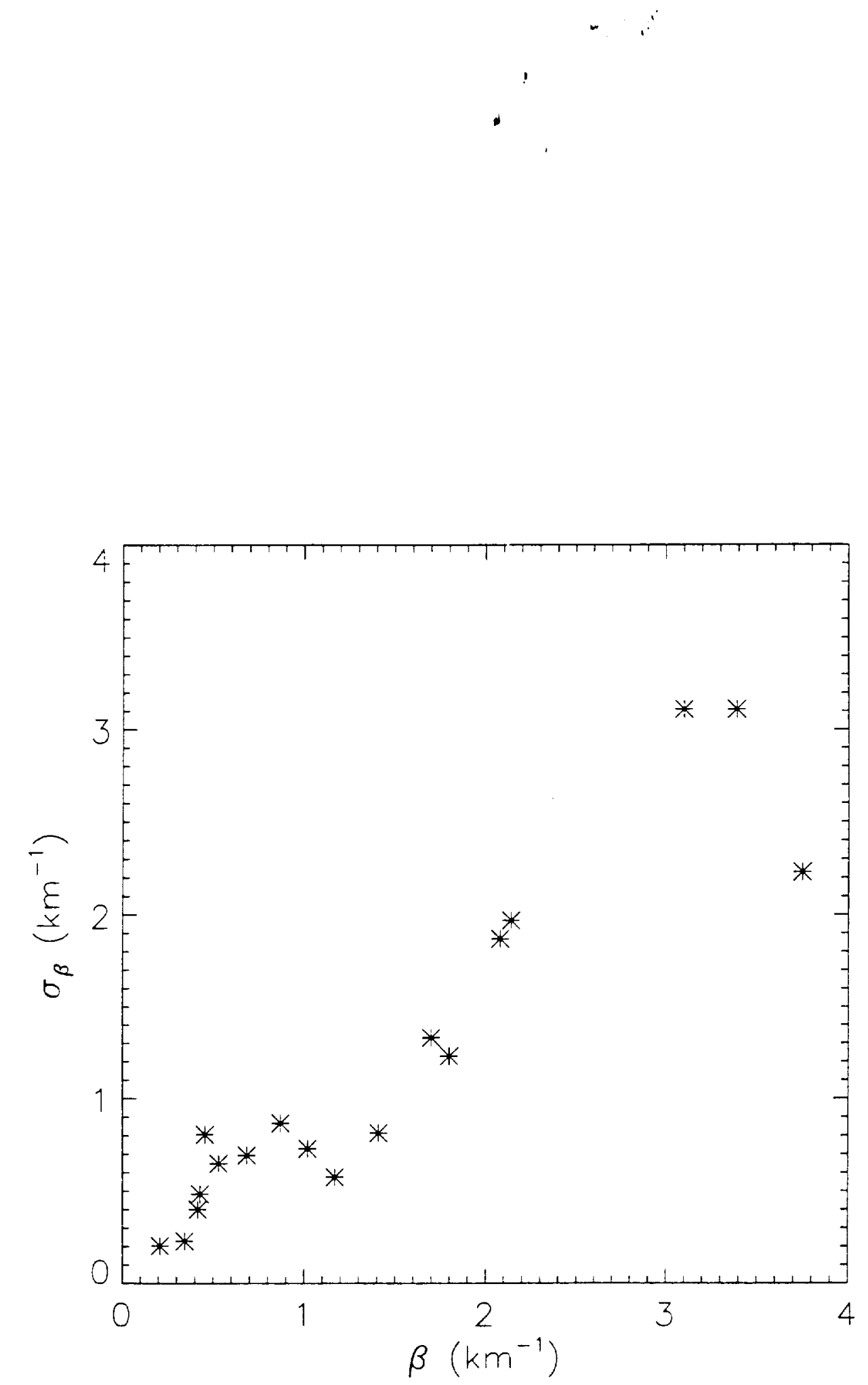



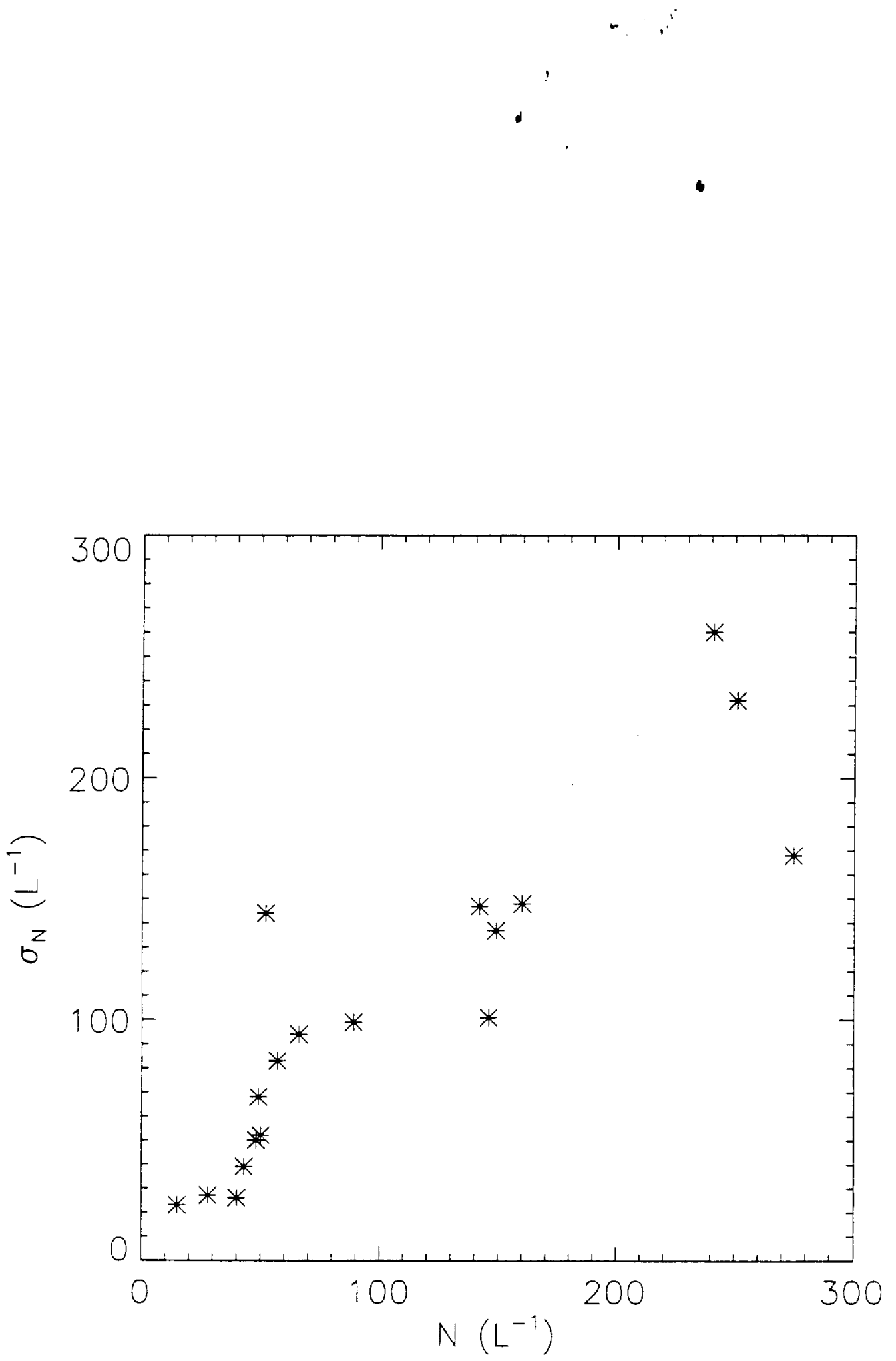


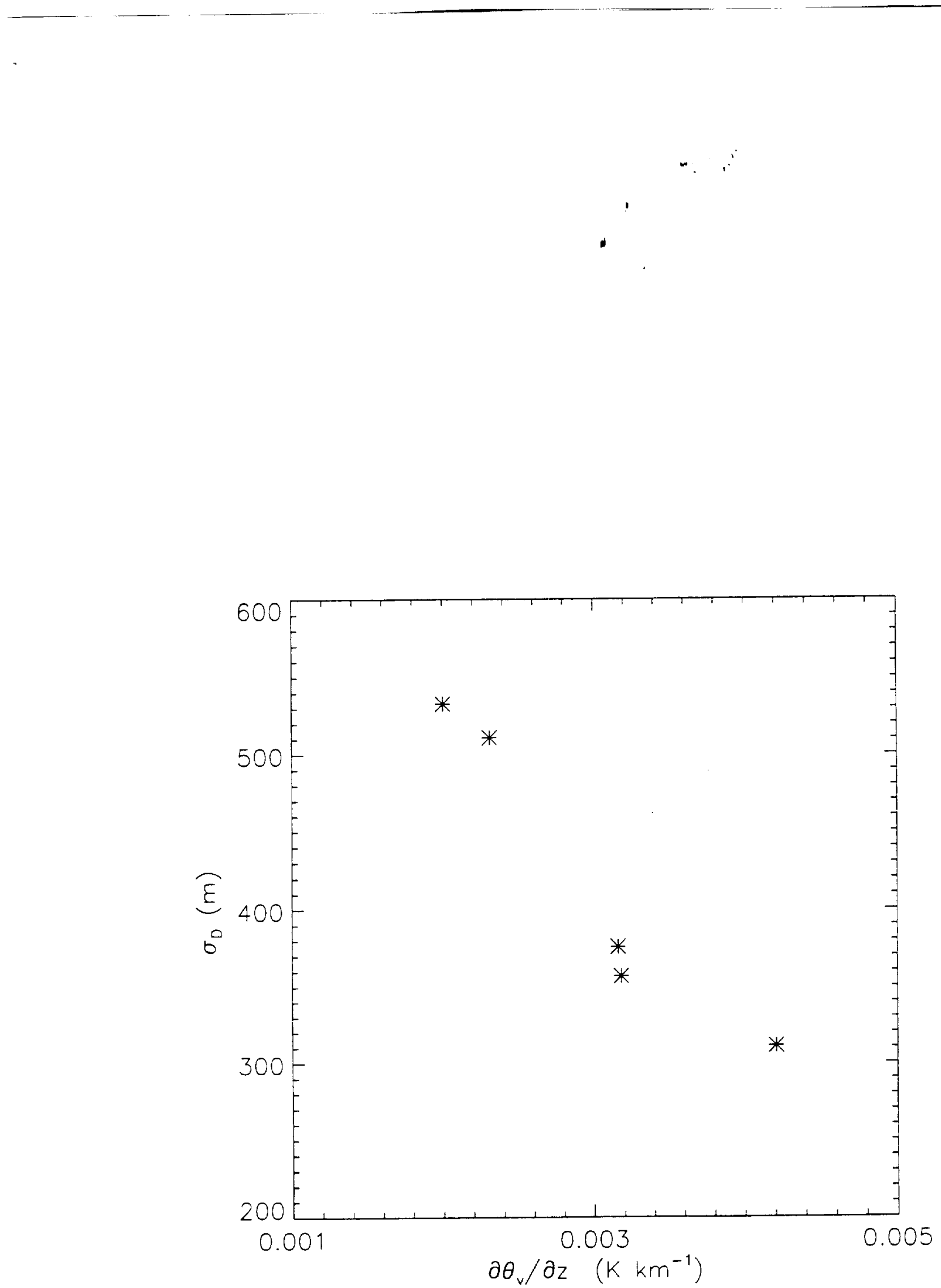

